\title{
Hallazgos morfológicos en casos fatales de síndrome cardiopulmonar por hantavirus. Estudio de 7 autopsias
}

\author{
Pablo Guzmán G., Oscar Tapia E., Miguel Villaseca H., Juan Araya O., \\ Lilia Antonio P., Bolívar Lee O. y Juan Roa S
}

\begin{abstract}
Universidad de La Frontera, Temuco, Chile.

Departamento de Anatomía Patológica, Facultad de Medicina.

Hospital Hernán Henríquez Aravena, Temuco, Chile. Unidad de Anatomía Patológica y Citopatología.

Trabajo financiado parcialmente por Proyecto DI09-0075 de la Dirección de Investigación y Desarrollo de la

Universidad de la Frontera.

Declaración de conflictos de interés: Los autores declaran no tener conflictos de interés.

Recibido: 5 de enero de 2010 Aceptado: 9 de agosto de 2010

Correspondencia a: Pablo Guzmán González pguzman@ufro.c
\end{abstract}

\section{Morphological findings in fatal cases of hantavirus cardiopulmonary syndrome. Report of 7 autopsies}

Introduction: Hantavirus cardiopulmonary syndrome (HCPS) is an acute infectious disease characterized by sudden cardiorespiratory failure and high mortality, caused by a RNA virus of the genus Hantavirus, family Bunyaviridae, $15 \%$ of Chilean cases have been detected in the Araucania Region. Objective: To determine in fatal cases of HCPS, clinical and morphological characteristics. Materials and Methods: Descriptive-retrospective analysis of seven fatal cases with postmortem study of HCPS, attended between 1997 and 2009 at the Hospital of Temuco, Chile. Results: Cases were young patients from rural areas, and presented as an illness of progressive respiratory failure, with leukocytosis, thrombocytopenia and bilateral interstitial pulmonary infiltrates. Main morphological findings were marked intersticial and intraalveolar pulmonary edema, with minimal epithelial injury and mononuclear cell intersticial infiltrate and mild edematous intersticial inflamatory process. Conclusions: Epidemiological, clinical and laboratory background allow to suspect HCPS. In fatal cases, the autopsy makes possible to discard other similar pathologies and provide tissue for confirmation of the disease.

Key words: Hantavirus, hantavirus cardiopulmonary syndrome, severe atypical pneumonias, autopsy.

Palabras clave: Hantavirus, síndrome cardio-pulmonar por hantavirus, neumonías atipicas graves, autopsia.

\section{Introducción}

$\mathrm{E}$ 1 síndrome cardiopulmonar por hantavirus (SCPH) es una enfermedad infecciosa aguda, endémica y estacional, descrita en el continente americano, que cursa con insuficiencia cardio-respiratoria de rápida instalación y alta mortalidad. Es causado por un virus ARN del género Hantavirus, familia Bunyaviridae, cuyo genoma viral está compuesto por tres segmentos que codifican para la transcriptasa viral, glicoproteínas de cubierta viral y proteínas nucleocapsulares. Morfológicamente, se presenta como partículas esféricas o irregulares de 80 a $120 \mathrm{~nm}$ de diámetro ${ }^{1}$. Es inactivado por calor, detergentes, radiación UV, solventes orgánicos y soluciones de hipoclorito ${ }^{2}$. El reservorio natural es el ratón de cola larga (Oligoryzomys longicaudatus), habitante frecuente de zonas rurales y boscosas del centro y sur de Chile. La principal vía de contagio es la inhalación de aerosoles provenientes de heces, orina y saliva de roedores portadores ${ }^{3}$.

En Chile, hasta el presente (junio 2010), se han registrado 664 casos, entre las regiones de Valparaíso y Aysén. El hantavirus causal es la variedad Andes. En la zona de la Araucanía se han registrado 99 casos $(15 \%)^{4}$. De los casos fallecidos, la mayoría poseía un diagnóstico premortem de SCPH; sin embargo, algunos de ellos sólo pudieron ser detectados y confirmados con posterioridad al examen de autopsia.

La necropsia en este tipo de patología cumple un importante rol educativo en lo respectivo a la correlación anátomo-clínica, también en la investigación clínica y en Salud Pública al detectar y diagnosticar estos cuadros infecciosos re-emergentes que pueden amenazar la salud de la comunidad. Sin embargo, este tipo de procedimiento requiere un alto nivel de bioseguridad, ya que reviste riesgos significativos, pues se ha demostrado transmisión por aerosoles de roedores de laboratorio a personal de laboratorio ${ }^{5}$ y contagio persona-persona ${ }^{6}$.

El objetivo de esta publicación es describir las principales características epidemiológicas, clínicas, de laboratorio, y particularmente los hallazgos morfológicos postmortem más significativos, observados en casos fatales de $\mathrm{SCPH}$.

\section{Material y Método}

Se revisaron, de manera retrospectiva, las siete fichas clínicas incluidos los protocolos de autopsia, de los pacientes fallecidos con diagnóstico de infección por hantavirus en el Hospital Hernán Henríquez Aravena (HHHA) 
de Temuco, Chile, en quienes además se practicó autopsia anátomo-clínica, reclutados desde el año 1997 a mayo del 2009. Los exámenes de laboratorio fueron realizados utilizando técnicas estandarizadas en el Laboratorio Central del HHHA. Los estudios radiográficos fueron interpretados por el médico clínico encargado del paciente. Las autopsias fueron realizadas, en promedio, con 11 horas postmortem (rango: 2 a $32 \mathrm{~h}$ ), por personal experimentado de la Unidad de Anatomía Patológica del HHHA y con protección adecuada para este tipo de procedimientos, según técnica de Virchow-Rokitansky modificada ${ }^{7}$. Los tamaños y pesos de las vísceras fueron obtenidos por métodos e instrumentos estándares y comparados con tablas de referencia ${ }^{8}$. A los cortes histológicos examinados se les realizó tinción histoquímica rutinaria de hematoxilina eosina, ácido peryódico de Schiff, Giemsa, Gram y Ziehl-Neelsen. No se realizaron estudios de microscopia electrónica ni inmuno-histoquímica específica, por no estar implementados en nuestro laboratorio. En todos los casos, el diagnóstico post necropsia resultó compatible con SCPH, enviándose muestras de hígado, corazón, bazo y pulmón al Laboratorio de Virología del Instituto de Salud Pública (ISP) donde se realizó la confirmación diagnóstica mediante técnicas serológicas de detección de anticuerpos IgM específicos contra hantavirus y mediante método de trascripción reversa acoplada con reacción de polimerasa en cadena (RPC).

\section{Resultados}

Hallazgos epidemiológicos. La edad promedio fue de 31 años, rango de 3 a 53 años. La mayoría de ellos provenía de sectores rurales, donde probablemente ocurrió el contagio. No hubo una distribución estacional en particular en el desarrollo de la enfermedad, como tampoco una diferencia marcada en el género del paciente (Tabla 1).

Hallazgos clínicos. El período prodrómico fue de 2 a 15 días, con un promedio de 6 días (Tabla 1). La mayoría cursó con febrículas o fiebre baja, vómitos, cefalea, dolor abdominal, mialgias, tos, polipnea y dificultad respiratoria de instalación aguda y evolución progresiva que concluyó con shock y muerte. El tiempo promedio desde el ingreso al HHHA hasta el deceso de los pacientes fue de 15 horas (rango 1 a 32 horas).

Hallazgos de laboratorio (Tabla 3). La mayoría de los casos mostró leucocitosis con neutrofilia y desviación a izquierda, linfopenia, plaquetopenia y cifras variables de hematocrito, aumento de transaminasas, láctico deshidrogenasa y en la mitad de los casos se observó aumento de creatininemia y de proteína $\mathrm{C}$ reactiva. La protrombinemia estaba disminuida. Las alteraciones más frecuentes en la radiografía de tórax fueron infiltrados difusos bilaterales y efusión pleural. El diagnóstico premortem se sospechó

Tabla 1. Características epidemiológicas de pacientes fallecidos por síndrome cardiopulmonar por hantavirus

\begin{tabular}{|c|c|c|c|c|c|c|c|}
\hline & Caso 1 & Caso 2 & Caso 3 & Caso 4 & Caso 5 & Caso 6 & Caso 7 \\
\hline Estación climática/año & Invierno/1997 & Invierno/2000 & Invierno/2001 & Verano/2002 & Primavera/2005 & Verano/2008 & Otoño/2009 \\
\hline Edad/sexo & 27 años/hombre & 30 años/hombre & 3 años/mujer & 21 años/mujer & 53 años/mujer & 34 años/hombre & 50 años/hombre \\
\hline Procedencia & $\begin{array}{l}\text { Rural cordillerano } \\
\text { (Purén) }\end{array}$ & $\begin{array}{l}\text { Rural cordillerano } \\
\text { (Curacautín) }\end{array}$ & $\begin{array}{l}\text { Urbano/costero } \\
\text { (Villarrica) }\end{array}$ & $\begin{array}{l}\text { Rural } \\
\text { (temporera) }\end{array}$ & $\begin{array}{l}\text { Rural/costero } \\
\text { (Curarrehue) }\end{array}$ & $\begin{array}{l}\text { Rural costero } \\
\text { (Villarrica) }\end{array}$ & Situación de calle \\
\hline Período prodrómico & 7 días & 3 días & 4 días & 15 días & 6 días & 2 días & 7 días \\
\hline
\end{tabular}

\begin{tabular}{|c|c|c|c|c|c|c|c|}
\hline & Caso 1 & Caso 2 & Caso 3 & Caso 4 & Caso 5 & Caso 6 & Caso 7 \\
\hline Fiebre $\left({ }^{\circ} \mathrm{C}\right)$ & 38,2 & 37,5 & 37,8 & 37 & 35,8 & 37,8 & 39,1 \\
\hline Vómitos & $\mathrm{Si}$ & No & $\mathrm{Si}$ & $\mathrm{Si}$ & No & $\mathrm{Si}$ & $\mathrm{Si}$ \\
\hline Cefalea & $\mathrm{Si}$ & $\mathrm{Si}$ & No & $\mathrm{Si}$ & $\mathrm{Si}$ & $\mathrm{Si}$ & $\mathrm{Si}$ \\
\hline Dolor abdominal & No & No & $\mathrm{Si}$ & $\mathrm{Si}$ & No & $\mathrm{Si}$ & $\mathrm{Si}$ \\
\hline Mialgias & No & $\mathrm{Si}$ & No & $\mathrm{Si}$ & $\mathrm{Si}$ & No & $\mathrm{Si}$ \\
\hline Hepato-esplenomegalia & No & No & No & No & No & No & No \\
\hline Tos & No & $\mathrm{Si}$ & $\mathrm{Si}$ & $\mathrm{Si}$ & $\mathrm{Si}$ & No & $\mathrm{Si}$ \\
\hline Polipnea & $\mathrm{Si}$ & $\mathrm{Si}$ & $\mathrm{Si}$ & $\mathrm{Si}$ & $\mathrm{Si}$ & $\mathrm{Si}$ & $\mathrm{Si}$ \\
\hline Distress respiratorio y shock & $\mathrm{Si}$ & $\mathrm{Si}$ & $\mathrm{Si}$ & $\mathrm{Si}$ & $\mathrm{Si}$ & $\mathrm{Si}$ & $\mathrm{Si}$ \\
\hline
\end{tabular}


en cuatro casos, uno de los cuales además tuvo una prueba positiva de anticuerpos IgM específicos contra hantavirus mediante inmunocromatografía (Tabla 3). Debido al corto periodo intrahospitalario, ninguno de los casos sospechosos tuvo una confirmación premortem por el Laboratorio de Referencia (ISP).

Hallazgos en autopsia. En el estudio postmortem se constató que todos los casos poseían buen estado nutricional, con masas musculares conservadas. Los principales hallazgos cardio-pulmonares se detallan en Tabla 4.

Cavidades pleurales: En 6 casos, las cavidades pleurales contenían líquido citrino o serohemático, en promedio $500 \mathrm{ml}$ (rango 100-1.610 ml). Pulmones: Los pulmones de cada caso en adultos, registraron en conjunto, un peso promedio de $1.984 \mathrm{~g}$ (rango 1.220-2.644 g). Superficie pleural rojo-violácea, de aspecto edematoso, con petequias pleurales aisladas y consistencia elástica, levemente aumentada. La superficie de corte era pardorojiza, brillante, homogénea, con drenaje de escaso líquido citrino-hemático (Figura 1). El examen microscópico reveló arquitectura alveolar conservada, con cavidades ocupadas por material proteináceo, eosinófilo, y de manera aislada, membranas hialinas fibrinosas y descamación de macrófagos (Figura 2A). El epitelio alveolar estaba casi intacto con neutrófilos escasos en el intersticio, alvéolos y vía aérea. Los tabiques alveolares poseían capilares hiperémicos, con elementos mieloides inmaduros y de aspecto inmunoblástico, que además infiltraban en tabiques. No se encontró vasculitis ni trombosis, tampoco inclusiones

\begin{tabular}{|c|c|c|c|c|c|c|c|}
\hline & Caso 1 & Caso 2 & Caso 3 & Caso 4 & Caso 5 & Caso 6 & Caso 7 \\
\hline \multicolumn{8}{|l|}{ Hemograma } \\
\hline Leucocitos & 10.200 & 5.000 & 26.200 & 28.500 & 17.000 & 24.000 & 22.160 \\
\hline Baciliformes & s/a & s/a & $21 \%$ & $20 \%$ & s/a & $\mathrm{s} / \mathrm{a}$ & $10 \%$ \\
\hline Neutrofilos & $\mathrm{s} / \mathrm{a}$ & s/a & $42 \%$ & $75 \%$ & $78.1 \%$ & $60.1 \%$ & $80 \%$ \\
\hline Linfocitos & s/a & s/a & $25 \%$ & $3 \%$ & $7.22 \%$ & $21.3 \%$ & $5 \%$ \\
\hline Hematocrito & 46,4 & 38,6 & 40 & $62.9 \%$ & $57 \%$ & $58,5 \%$ & $36,4 \%$ \\
\hline Plaquetas & 45.000 & 170.000 & 21.000 & 54.300 & 114.000 & 38.200 & 85.000 \\
\hline \multicolumn{8}{|l|}{ Bioquímico } \\
\hline PCR (mg/L) & $s / a$ & s/a & s/a & 7,6 & 48 & 19,1 & 256 \\
\hline GOT (U/L) & s/a & s/a & 273 & 887 & 195 & 413 & 2321 \\
\hline GPT (U/L) & s/a & s/a & 104 & 327 & 79 & 355 & 552 \\
\hline $\mathrm{LDH}(\mathrm{U} / \mathrm{L})$ & elevada & s/a & s/a & 2057 & s/a & s/a & 1385 \\
\hline $\begin{array}{l}\text { Creatininemia } \\
\text { (mg/100 mL) }\end{array}$ & 0,9 & s/a & 0.5 & 3.5 & 3.61 & 2.0 & 1.36 \\
\hline Protrombina (\%) & normal & s/a & 39 & s/a & 68 & 19 & 57 \\
\hline $\begin{array}{l}\text { Radiografía de } \\
\text { tórax }\end{array}$ & $\begin{array}{l}\text { Extenso infiltrado } \\
\text { pulmonar difuso, } \\
\text { bilateral }\end{array}$ & $\mathrm{s} / \mathrm{a}$ & $\begin{array}{l}\text { Bronconeumonia } \\
\text { Basal derecha y } \\
\text { derrame pleural }\end{array}$ & $\begin{array}{l}\text { Infiltrados pulmo- } \\
\text { nares bilaterales. } \\
\text { de tipo congestivo }\end{array}$ & $\begin{array}{l}\text { Infiltrado inters- } \\
\text { ticial bilateral en } \\
\text { tercio medio e } \\
\text { inferior }\end{array}$ & $\begin{array}{l}\text { Signos de edema } \\
\text { pulmonar }\end{array}$ & $\mathrm{s} / \mathrm{a}$ \\
\hline $\begin{array}{l}\text { Sospecha } \\
\text { diagnóstica } \\
\text { premortem }\end{array}$ & No & $\begin{array}{l}\text { Si, por antec } \\
\text { clínicos }\end{array}$ & No & $\begin{array}{l}\text { Si, por antec } \\
\text { clínica y de labo- } \\
\text { ratorio }\end{array}$ & $\begin{array}{l}\text { Si, por antec } \\
\text { clínica y de labo- } \\
\text { ratorio }\end{array}$ & $\begin{array}{l}\text { Si, por antec } \\
\text { clínicos y de } \\
\text { laboratorio } \\
\text { (IgM + por lcg) }\end{array}$ & No \\
\hline $\begin{array}{l}\text { Diagnósticos } \\
\text { clínicos en } \\
\text { solicitud de } \\
\text { autopsia }\end{array}$ & $\begin{array}{l}\text { Neumonía bilate- } \\
\text { ral aguda } \\
\text { Shock séptico }\end{array}$ & $\mathrm{SCPH}$ & $\begin{array}{l}\text { Shock séptico } \\
\text { Abdomen agudo }\end{array}$ & $\mathrm{SCPH}$ & $\begin{array}{l}\text { Neumopatía } \\
\text { intersticial } \\
\text { Obs. Hanta }\end{array}$ & $\mathrm{SCPH}$ & $\begin{array}{l}\text { Sepsis de foco } \\
\text { pulmonar }\end{array}$ \\
\hline $\begin{array}{l}\text { Conformación } \\
\text { diagnóstica (ISP) }\end{array}$ & $\begin{array}{l}\lg M+\text {, postmor- } \\
\text { tem }\end{array}$ & $\begin{array}{l}\lg M+, \text { postmor- } \\
\text { tem }\end{array}$ & $\begin{array}{l}\lg M+, \text { postmor- } \\
\text { tem }\end{array}$ & $\begin{array}{l}\lg M+\text {, postmor- } \\
\text { tem }\end{array}$ & $\begin{array}{l}\lg M+, \text { postmor- } \\
\text { tem }\end{array}$ & $\begin{array}{l}\lg M+, \text { postmor- } \\
\text { tem }\end{array}$ & $\begin{array}{l}\lg M+\text {, postmor- } \\
\text { tem }\end{array}$ \\
\hline
\end{tabular}


Tabla 4. Principales hallazgos morfológicos cardiopulmonares en casos fatales de SCPH

\begin{tabular}{|c|c|c|c|}
\hline & Edad/sexo & Macroscopia & Microscopia \\
\hline Caso 1 & $\begin{array}{l}27 \text { años } \\
\text { Hombre }\end{array}$ & $\begin{array}{l}\text { Efusión pleural bilateral ( } 300 \mathrm{ml}) \\
\text { PD: } 1.362 \mathrm{~g} \text {, Pl: } 1.282 \mathrm{~g} \text {, con focos hemorrágicos de consistencia au- } \\
\text { mentada y elástica. } \\
\text { Corazón: } 440 \mathrm{~g} \text {, epicardio con petequias aisladas y hemorragias en- } \\
\text { docárdicas }\end{array}$ & \multirow{7}{*}{$\begin{array}{l}\text { Pulmón: Engrosamiento de tabiques interalveolares con hiperemia ca- } \\
\text { pilar e infiltrado de elementos mieloides inmaduros. Espacios alveolares } \\
\text { irregularmente distendidos con exudado proteináceo, fibrina, macró- } \\
\text { fagos, elementos mieloides inmaduros y escasa hemorragia alveolar. } \\
\text { Presencia aislada de membranas hialinas. Mínimas alteraciones de } \\
\text { neumocitos I. No se observa hiperplasia de neumocitos II, atelectasias } \\
\text { ni signos de organización. } \\
\text { Corazón: Fibras musculares con picnosis nuclear y basofilia citoplas- } \\
\text { mática aislada. Edema intersticial leve a moderado, con infiltrado de } \\
\text { elementos mieloides inmaduros. }\end{array}$} \\
\hline Caso 2 & $\begin{array}{l}30 \text { años } \\
\text { Hombre }\end{array}$ & $\begin{array}{l}\text { Efusión pleural bilateral }(1.610 \mathrm{ml}) \\
\text { PD: } 1.060 \mathrm{~g} \text {, Pl: } 1.064 \mathrm{~g} \text {, con focos hemorrágicos de consistencia au- } \\
\text { mentada y elástica. } \\
\text { Corazón: } 426 \mathrm{~g} \text {, sin lesiones evidentes, paredes flácidas. }\end{array}$ & \\
\hline Caso 3 & $\begin{array}{l}3 \text { años } \\
\text { Mujer }\end{array}$ & $\begin{array}{l}\text { Efusión pleural sero-hemática bilateral ( } 200 \mathrm{ml} \text { ) } \\
\text { PD: } 168 \mathrm{~g} \text {, Pl: } 148 \mathrm{~g} \text {, con focos hemorrágicos, consistencia aumentada, } \\
\text { no crepitante. } \\
\text { Corazón: } 68 \mathrm{~g} \text {, sin lesiones evidentes. }\end{array}$ & \\
\hline Caso 4 & $\begin{array}{l}21 \text { años } \\
\text { Mujer }\end{array}$ & $\begin{array}{l}\text { Efusión pleural bilateral ( } 100 \mathrm{ml}) \text {. } \\
\text { PD: } 1.122 \mathrm{~g} \text {, Pl: } 826 \mathrm{~g} \text {, con focos hemorrágicos, equimosis, consistencia } \\
\text { aumentada y edematoso. Corazón: } 232 \mathrm{~g} \text {, epicardio opaco con escasas } \\
\text { petequias. }\end{array}$ & \\
\hline Caso 5 & $\begin{array}{l}53 \text { años } \\
\text { Mujer }\end{array}$ & $\begin{array}{l}\text { Efusión pleural sero-hemático bilateral }(570 \mathrm{ml}) \\
\text { PD: } 670 \mathrm{~g} \text {, Pl: } 550 \mathrm{~g} \text {. Superficie rojo violácea con petequias y consis- } \\
\text { tencia aumentada. } \\
\text { Corazón: } 320 \mathrm{~g} \text {, sin lesiones evidentes. }\end{array}$ & \\
\hline Caso 6 & $\begin{array}{l}34 \text { años } \\
\text { Hombre }\end{array}$ & $\begin{array}{l}\text { Efusión pleural sero-hemática bilateral }(1.100 \mathrm{ml}) \\
\text { PD: } 1.040 \mathrm{~g} \text {, Pl: } 1.048 \mathrm{~g} \text {. Petequias subpleurales, infiltración hemorrá- } \\
\text { gica, consistencia aumentada y elástica. } \\
\text { Corazón: } 340 \mathrm{~g} \text {, endocardio con petequias y hemorragias aisladas. }\end{array}$ & \\
\hline Caso 7 & $\begin{array}{l}43 \text { años } \\
\text { Hombre }\end{array}$ & $\begin{array}{l}\text { Cavidades pleurales libres. } \\
\text { PD: } 962 \text { g, Pl: } 920 \text { g. Aspecto edematoso y consistencia aumentada. } \\
\text { Corazón: } 575 \text { g, sin lesiones evidentes, paredes flácidas. }\end{array}$ & \\
\hline
\end{tabular}

virales o efectos citopáticos. Las tinciones especiales resultaron negativas para microorganismos patógenos (Figura 2B). Conclusión: Edema pulmonar con membranas hialinas aisladas. Células de tipo inmunoblastos en el espacio intravascular.

Corazón: El peso promedio en adultos fue de $388 \mathrm{~g}$, presentaba aspecto general conservado con petequias epicárdicas aisladas. El miocardio presentaba infiltración intersticial exudativa y con elementos celulares mononucleares inmaduros (Figura 3A). En escasas y aisladas fibras miocárdicas se encontró picnosis nuclear y basofilia citoplasmática.

Ganglios linfáticos: Adenopatías mediastínicas y mesentéricas, con hiperplasia linfoide folicular y sinusal. Células de tipo inmunoblastos en el espacio intravascular.

Higado: Se encontró hepatomegalia variable en todos los casos, con $1.730 \mathrm{~g}$ de peso promedio en adultos. Superficie rojo violáceo, de aspecto tumefacto. Microscopia con conservación de la arquitectura trabecular e infiltrado mononuclear en triadas portales. Células de tipo inmunoblastos en el espacio intravascular (Figura 3B).

Médula ósea hematopoyética: Aumento moderado de

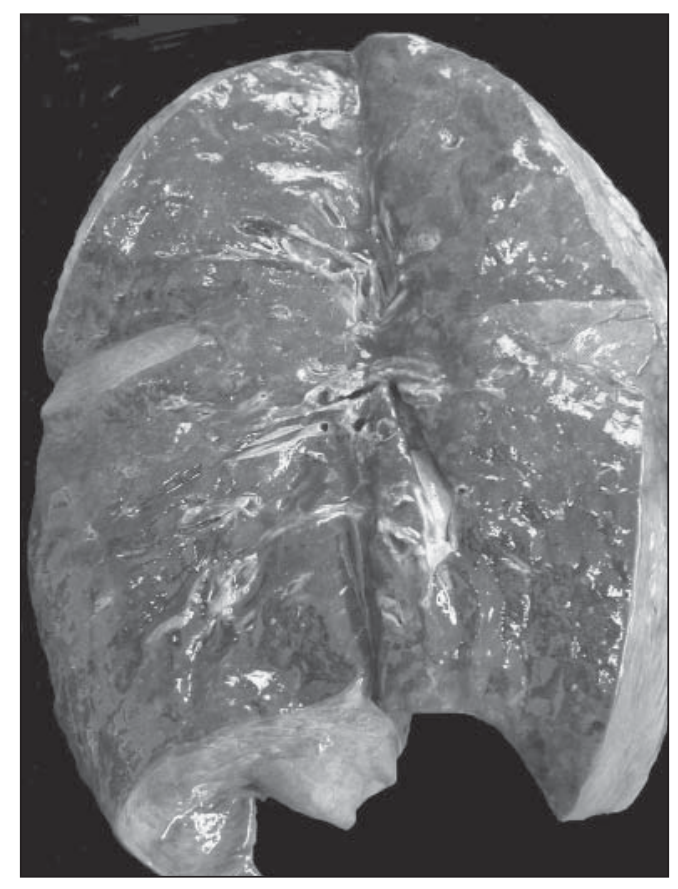

Figura 1. Fotografía de superficie de corte pulmonar, de aspecto edematoso y con focos hemorrágicos aislados. 
la celularidad y de la serie mieloide inmadura y megacarioblástica, con escasa expresión de la serie granulocítica (Figura 3C y 3D). Células de tipo inmunoblastos en el espacio intravascular.

Bazo: Peso promedio en adultos de $220 \mathrm{~g}$, tumefacto, con hiperplasia de pulpa roja. Células de tipo inmunoblastos en el espacio intravascular y en la pulpa roja.

Riñones: Todos poseían una estructura macroscópica conservada, con degeneración hidrópica del epitelio tubular.

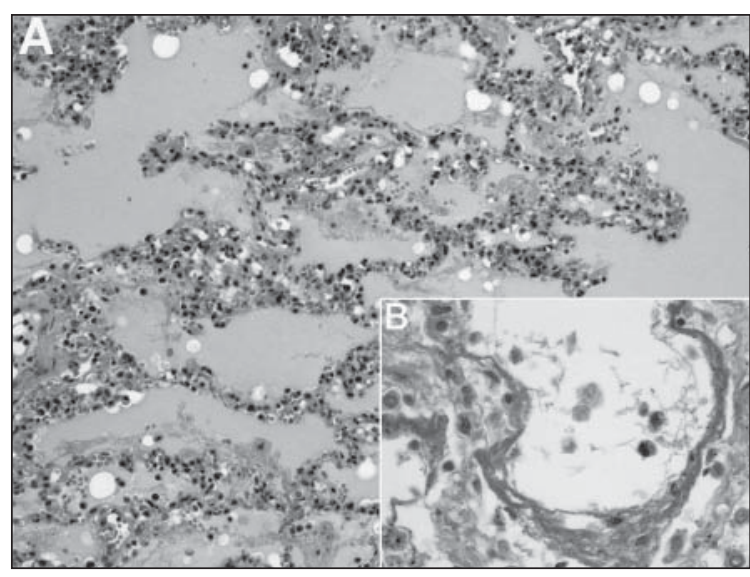

Figura 2. Microfotografía pulmonar con extenso exudado intralaveolar y tabique con infiltrado mononuclear (A, H\&E, 20x). En recuadro (B, H\&E, 40x), membranas hialinas y células de tipo inmunoblastos.
Otros tejidos: En piel, algunos presentaban cicatrices quirúrgicas, sin otras lesiones significativas. Encéfalo con signos de edema en dos casos, sin alteraciones histológicas. Tracto gastrointestinal sólo con petequias aisladas en su mucosa. Vía biliar y páncreas sin lesiones identificables.

Las muestras de pulmón, hígado y bazo enviadas al Instituto de Salud Pública de Chile, sección Virología, confirmaron la presencia del genoma de hantavirus variedad Andes en todas ellas.

\section{Discusión}

El SCPH en América es una enfermedad endémica con más de 2.000 casos registrados entre 1993 y el año 2004'. En Chile se han presentado 664 casos desde 1975 a la fecha. Entre los años 1998 y 2008 se han reportado en promedio, 54 casos anuales, con un rango de 26 casos en 1999 y 81 casos en el año 2001. La distribución abarca desde las regiones de Valparaíso a Aysén. Afecta predominantemente al sexo masculino $(71 \%)$ y la edad promedio es cercana a los 32 años. La letalidad del SCPH disminuyó progresivamente desde $\sim 60 \%$ a mediados de los años noventa a $\sim 30 \%$ en el año 2005 , cifra que se mantiene $\sin$ grandes variaciones hasta la actualidad ${ }^{3,4}$.

La infección por hantavirus puede manifestarse como cuadros de sintomatología mínima o ausente, hasta insuficiencia respiratoria grave y progresiva o SCPH. Este último posee un período de incubación de 8 a 34 días y síntomas prodrómicos consistentes en cefalea, fiebre y mialgias; luego sobreviene una fase cardiopulmonar con edema pulmonar agudo, taquicardia, taquipnea y escasos hallazgos en la radiografía de tórax. Los casos graves cursan además con depresión miocárdica e hipotensión arterial. Las mayores alteraciones de laboratorio son: hemo-concentración, trombocitopenia, leucocitosis y presencia de inmunoblastos. La confirmación diagnóstica se realiza con estudios serológicos (anticuerpos IgM e IgG específicos contra hantavirus), detección de material genético viral mediante RPC y técnicas de inmunohistoquímica contra antígenos virales en tejidos ${ }^{3,10}$.

Nuestros casos fueron, en promedio, algunos años más jóvenes que los publicados en otras series ${ }^{11,12}$, y además incluye un caso pediátrico cuyos hallazgos fueron similares a los de adultos.

Las alteraciones morfológicas de los 7 casos afectaron predominantemente al pulmón y corazón, y concordaron con lo descrito en otras publicaciones ${ }^{11-13}$. Los pulmones duplicaban y hasta triplicaban su peso normal a expensas de un edema acentuado, bilateral y difuso. Todos se acompañaron de efusión pleural. Estos hallazgos y las escasas alteraciones renales, confirman que el principal 
órgano afectado es el pulmón, no así en otras infecciones por hantavirus, como la fiebre hemorrágica con síndrome renal (FHSR), en la cual predomina la necrosis hemorrágica medular renal, hemorragia auricular derecha y edema retroperitoneal ${ }^{14}$, alteraciones que no se encontraron en ninguno de los casos de SCPH analizados.

En la microscopia óptica pulmonar se observaron alteraciones similares pero distinguibles del daño alveolar difuso (DAD) y del síndrome de dificultad respiratoria del adulto (SDRA). Nuestros hallazgos -acentuado edema intra-alveolar e intersticial asociado a infiltración mononuclear y de tipo inmunoblastos, relativa indemnidad de los neumocitos y depósito aislado de material fibrinoideo de tipo membrana hialina intra-alveolar, sin detritus celulares-difieren del DAD en el cual existe extensa destrucción de neumocitos tipo I, hiperplasia de neumocitos tipo II, infiltración polimorfonuclear neutrófila y alveolitis fibrosante ${ }^{15}$. Es probable entonces que el SCPH represente un proceso patológico diferente al DAD o evolucione como una forma fulminante de $\mathrm{DAD}$, en la cual el deceso ocurre antes que se constituya el daño en el revestimiento alveolar y el desarrollo de abundantes membranas hialinas. Los hallazgos microscópicos también nos permiten descartan una neumonía intersticial aguda pues no se encontró signos de organización intersticial o intra-alveolar, atelectasias ni proliferación de neumocitos tipo II $^{12,13}$. La presencia de material proteináceo intra-alveolar, efusión pleural y hemo-concentración, con células epiteliales y endoteliales alveolares indemnes y la identificación del virus en el endotelio capilar pulmonar por microscopia electrónica ${ }^{16}$, es compatible con un síndrome de extravasación capilar, mecanismo fisiopatológico propuesto para el FHSR, que en el caso del SCPH tendría al pulmón como principal órgano afectado ${ }^{17}$.

El corazón presentaba, en la mayoría de los casos, aumento de peso con petequias epicárdicas, edema leve a moderado e infiltración inflamatoria intersticial, constituida en su mayoría por células mieloides mononucleares, lo que coincide con los hallazgos publicados ${ }^{18}$. Estas alteraciones, menos acentuados que los cambios pulmonares, contrastan con la marcada disfunción miocárdica y shock premortem. Probablemente el corto período de hipotensión arterial e hipoxemia, menor a 24 horas, impidió la aparición de cambios más llamativos.

Ninguno de los casos presentó hemorragias extensas en las vísceras y mucosas, a pesar de la coagulopatía observable en los exámenes de laboratorio. En el FHSR son frecuentes las petequias cutáneas, hematuria y hemorragias subconjuntivales, gastrointestinales y viscerales ${ }^{14}$. Hasta ahora, no está claro si la coagulopatía del SCPH es cualitativamente diferente o sólo cuantitativamente diferente de la del FHSR, aunque el hecho de encontrar signos regenerativos medulares en SCPH sugiere una probable causa de incremento del consumo o secuestro.
En todos los pacientes se observó la presencia de células mononucleares inmaduras de tipo inmunoblastos, a nivel intravascular y en ocasiones intersticial en el bazo, médula ósea, pulmón, hígado y ganglios linfáticos. El análisis inmuno-fenotípico del infiltrado inflamatorio pulmonar ha demostrado células de tipo monocito/ macrófago y linfocitos T CD4 y CD8, estos últimos en relación 2:1, con escasas células citolíticas naturales CD16 y ausencia de linfocitos $\mathrm{B}^{17}$. De manera similar, el miocárdico presenta infiltrado de macrófagos CD68 y un significativo número de linfocitos CD45RO, linfocitos $\mathrm{T}$ CD4 y linfocitos B CD20 ${ }^{18}$. Este infiltrado celular sería responsable de la producción de citoquinas como factor de necrosis tumoral $\alpha$, interleuquinas e interferón $\gamma$. Además, el virus puede evadir la respuesta inmune antiviral del hospedero mediante glucoproteínas estructurales ${ }^{16}$.

La principal teoría patogénica incluye múltiples elementos relacionados, tanto con la virulencia del hantavirus al evadir a la respuesta inmune, como también la acción citotóxica directa de los linfocitos T CD8 activados sobre células endoteliales, que contribuyen al aumento de la permeabilidad capilar pulmonar y serían responsables además de la depresión miocárdica y el shock en SCPH fatales ${ }^{16-19}$. Es importante mencionar también otros elementos que influyen de manera negativa, como el edema pulmonar y efusión pleural, que reducen el llene diastólico y la vasodilatación periférica debido a la hipoxemia acentuada ${ }^{19}$.

La infección por hantavirus está registrada en un nivel 3 de bioseguridad de la clasificación del Centro de Control de Enfermedades de Estados Unidos, es decir, corresponde a aquellos agentes infecciosos que provocan enfermedades graves, potencialmente mortales, secundarias a exposición respiratoria. En este nivel se recomienda para los prosectores (un patólogo y un ayudante entrenado) uso de gorro tipo quirúrgico, protección ocular y/o facial, doble guante, mascarilla y bata quirúrgica desechable, respiradores con purificadores de aire y filtros HEPA (high-efficiency particulate air), pechera impermeable y cubre calzado. Durante el procedimiento se aconseja evitar salpicaduras o generación de aerosoles, estricto cumplimiento de las medidas universales con sangre y fluidos corporales, incineración de desechos sólidos, tratamiento de residuos líquidos y descontaminación de superficies con solución clorada. El pabellón de autopsia debe tener acceso restringido, flujo de aire unidireccional con extractores externos y diferentes puertas de entrada y salida. Estas medidas, aparentemente exageradas, resultan más que prudentes, considerando la poca información respecto a bioseguridad para el personal que realiza este tipo de autopsias y las potencialmente graves consecuencias del contagio ${ }^{20,21}$.

Considerando las manifestaciones clínicas, características epidemiológicas y exámenes de laboratorio de 
un paciente joven previamente sano, que inicia falla cardio-respiratoria progresiva, permite una alta sospecha del cuadro, el que debe finalmente ser confirmado con tests serológicos específicos. La necropsia en estos casos es una herramienta muy útil para el entendimiento de la enfermedad y también jugaría un rol fundamental en el diagnóstico de esta patología en casos no sospechados, al aportar hallazgos característicos, como marcado edema intersticial e intra-alveolar pulmonar, mínimo daño epitelial, membranas hialinas fibrinoides ocasionales e infiltrado mononuclear de tipo inmunoblastos; este último se observa también en el miocardio. Estos hallazgos no se encuentran en otros cuadros clínicos diferenciales como neumonías atípicas graves por Legionella pneumophila, Mycoplasma pneumoniae, Chlamydophila pneumoniae, Leptospira spp, virus influenza y neumopatías por Streptococcus pneumoniae, ni tampoco en patología no pulmonar como insuficiencia cardíaca, abdomen agudo, pielonefritis aguda, fiebre tifoidea, triquinosis y meningococcemia ${ }^{3}$.

En resumen, presentamos la mayor serie nacional de casos de autopsia reportada a la fecha en $\mathrm{SCPH}$, los que poseen características epidemiológicas, clínicas, de laboratorio y principalmente hallazgos morfológicos postmortem propios, que permiten diferenciarlos de cuadros clínicos similares.

\section{Resumen}

Introducción: El síndrome cardiopulmonar por hantavirus (SCPH) es una enfermedad infecciosa aguda, caracterizada por insuficiencia cardio-respiratoria súbita y alta mortalidad, causada por un virus ARN del género Hantavirus, familia Bunyaviridae. Un 15\% de los casos chilenos ha sido pesquisado en la Araucanía. Objetivo: Conocer en casos fatales de SCPH, sus características clínicas y morfológicas. Material y Método: Estudio descriptivo-retrospectivo de siete casos fatales con examen postmortem, de SCPH, atendidos entre 1997 y 2009 en el Hospital Regional de Temuco. Resultados: Los casos fueron principalmente pacientes jóvenes, rurales, con un cuadro de compromiso respiratorio progresivo, con leucocitosis, trombopenia e infiltrado pulmonar intersticial bilateral. Los principales hallazgos histopatológicos fueron un acentuado edema pulmonar intra-alveolar e intersticial, con escaso daño epitelial e infiltrado mononuclear y leve edema miocárdico con infiltrado mononuclear. Conclusiones: Los antecedentes epidemiológicos, clínicos y laboratorio permiten sospechar SCPH. En los casos fatales la autopsia permite diferenciar el SCPH de otras patologías similares y aporta tejidos para confirmar el diagnóstico.

\section{Referencias}

1.- Meissner J, Rowe J, Borucki M, St Jeor S. Complete nucleotide sequence of a Chilean hantavirus. Virus Res 2002; 89:

131-43.

2.- Kraus A, Priemer C, Heider H, Krüger D, Ulrich R. Inactivation of hantan virus-containing samples for subsequent investigations outside biosafety level 3 facilities. Intervirology 2005; 48: 255-61.

3.- $\quad$ Sotomayor V, Olea A, Labraña M (eds.). Diagnóstico y manejo del síndrome cardiopulmonar por hantavirus. Chile-2007. Rev Chil Infect 2009; 1: 68-86.

4.- Boletín Epidemiológico de Hantavirus. Situación al 24 de junio de 2010. Departamento de Epidemiología. Ministerio de salud. http://epi.minsal.cl/epi/html/bolets/reportes/ Hantavirus/Hantavirus.pdf (acccedido julio 2010)

5.- Shi X, McCaughey C, Elliot M. Genetic characterisation of a hantavirus isolated from a laboratory-acquired infection. J Med Virol 2003; 71: 105-9.

6.- Martínez P, Bellomo C, San Juan J, Pinna D, Forlenza R, Elder M, et al. Person-to-person transmisión of Andes virus. Emerg Infect Dis 2005; 11: 1848-53.

7.- Finkbeiner W, Ursell P, Davis R. Chapter 4: Basic Postmortem Examination. Autopsy Pathology. A Manual and Atlas. First edition. Philadelphia. Ed Churchill Livingstone 2004, 41-65.

8.- Finkbeiner W, Ursell P, Davis R. Appendix B. Measures, weights and assesment of growth and development. Autopsy Pathology. A Manual and Atlas. First edition. Philadelphia. Ed Churchill Livingstone 2004: 41-65.

9.- Bi F, Formenty P, Roth C. Hantavirus infection: a review and global update. $J$ Infect Dev Ctries 2008; 2: 3-23.

10.- Jonsson C, Hooper J, Mertz G. Treatment of hantavirus pulmonary syndrome. Antiviral Res 2008; 78: 162-9.

11.- Nolte K, Feddersen R, Foucar K, Zaki S, Koster F, Madar D, et al. Hantavirus pulmonary syndrome in the United States: a pathological description of a disease caused by a new agent. Hum-Pathol 1995; 26: 110-20.

12.- Colby T, Zaki S, Feddersen R, Nolte K. Hantavirus pulmonary syndrome is distinguishable from acute interstitial pneumonia. Arch Pathol Lab Med 2000; 124:
1463-6.

13.- Zaki S, Greer P, Coffield L, Goldsmith C, Nolte K, Foucar K, et al. Hantavirus pulmonary syndrome. Pathogenesis of an emerging infectious disease. Am J Pathol 1995 146: 552-79.

14.- Steer A. Pathology of hemorragic fever: a comparision of the findings; 1951 and 1952. Am J Pathol 1955; 31: 201-21.

15.- Tomashefski JF Jr. Pulmonary pathology of acute respiratory distress syndrome. Clin Chest Med 2000; 21: 435-66.

16.- Gavrilovskaya I, Gorbunova E, Mackow N, Mackow E. Hantaviruses direct endothelial cell permeability by sensitizing cells to the vascular permeability factor VEGF, while angiopoietin 1 and sphingosine 1-phosphate inhibit hantavirus-direct permeability. J Virol 2008; 82: 5797-806.

17.- Terajima M, Hayasaka D, Maeda K, Ennis F. Immunopathogenesis of hantavirus pulmonary syndrome and hemorrhagic fever with renal syndrome: Do $\mathrm{CD}^{+} \mathrm{T}$ cells trigger capillary leakage in viral hemorragic fevers? Immunol Lett 2007; 113: 117-20.

18.- Saggioro F, Rossi M, Duarte M, Martin C, Alves V, Moreli M. et al. Hantavirus 
infection induces a typical myocarditis that may be responsible for myocardial depression and shock in hantavirus pulmonary syndrome. J Infect Dis $2007 ; 195$ : 1541-9.

19.- Borges A, Figueiredo L. Mechanisms of shock in hantavirus pulmonary syndrome. Curr Opin Infect Dis 2008; 21: 293-7.

20.- Centers for Disease Control and Prevention \& National Institutes of Health: Biosafety in Microbiological and Biomedical Laboratories (ed 5). Washington, U.S.
Department of Health and Human Services, 2007.

21.- Nolte K, Foucar K, Richmond J. Hantaviral biosafety issues in the autopsy room and laboratory: Concerns and recommendations. Hum Pathol 1996; 27: 1253-4. 